\title{
Benefits of demands control in a smart-grid to compensate the volatility of non-conventional energies
}

\author{
Beneficios de controlar demandas en un smart-grid para compensar la volatilidad de las \\ energías no-convencionales
}

\author{
C. Risso (iD ${ }^{1 *}$ \\ ${ }^{1}$ Facultad de Ingeniería, Universidad de la República. Julio Herrera y Reissig 565. C. P. 11330. Montevideo, Uruguay.
}

\author{
CITE THIS ARTICLE AS: \\ C. Risso, "Benefits of \\ demands control in a \\ smart-grid to compensate \\ the volatility of \\ non-conventional \\ energies", Revista Facultad \\ de Ingeniería Universidad de \\ Antioquia, no. 93, pp. 19-31, \\ Oct-Dec 2019. [Online]. \\ Available: \\ https://www.doi.org/ \\ 10.17533/10.17533/ \\ udea.redin. 20190404
}

\section{ARTICLE INFO:}

Received: November 19 , 2018

Accepted: April 26, 2019

Available online: April 26, 2019

\section{KEYWORDS:}

Wind-power, smart-cities, short-term dispatch

Energía-eólica, ciudades-inteligentes, despacho al corto-plazo
ABSTRACT: Uruguay is a leader in the usage of renewable energies, getting $96 \%$ of its electricity from an assorted assemble of such sources with an increasing percentage of non-conventional energies, of wind power mostly. As clean and financially stable as they are, non-conventional energies have weaknesses. Unlike thermic and most hydro-sources, wind and solar energies are not controllable,are intermittent and uncertain some hours ahead, complicating the short-term operation and maintenance of electrical systems. This work explores how to use smart-grids capabilities to adjust electricity demand as a hedge against novel short-position risks in the Uruguayan electricity market coming from the volatility of non-conventional renewables. This approach uses combinatorial optimization dispatch models to quantitatively assess benefits resulting from having demand control. Results show that for the Uruguayan context, the benefits are not only due to savings in production costs (generation). Smart-grid optimal dispatch-schedules are also less stressing regarding the operation of the grid itself.

RESUMEN: Uruguay es líder en el uso de energías renovables, atendiendo el $96 \%$ de su demanda eléctrica con una mezcla de fuentes de este tipo, con crecimiento sostenido de renovables no-convencionales, de energía eólica fundamentalmente. Aunque limpias y ajenas a los vaivenes financieros, las no-convencionales presentan debilidades. A diferencia de las térmicas e hidráulicas, las energías eólica y solar no son controlables, son intermitentes e inciertas en las horas próximas, complicando la planificación, operación y mantenimiento al corto-plazo del sistema eléctrico. Este trabajo explora cómo usar las capacidades de los smart-grids para ajustar la demanda de electricidad, creando una cobertura contra esas nuevas posiciones de riesgo al corto-plazo en el mercado eléctrico uruguayo provenientes de la volatilidad de las renovables no-convencionales. La aproximación usa modelos de optimización combinatoria del despacho para cuantificar los beneficios resultantes del control de la demanda. Los resultados muestran que para el contexto Uruguayo, los beneficios no sólo provienen de los ahorros en producción (generación). La planificación óptima del despacho en smart-grids también resulta menos estresante para la operación de la misma red.

\section{Introduction}

This paper is an expanded version of our previous work [1]. The article expands the state-of-the art analysis to emphasize the relevance of this approach when compared with econometrics. Besides, models' details are extended, so is the analysis of the convenience of standard tools to solve associated problems, both in terms of performance

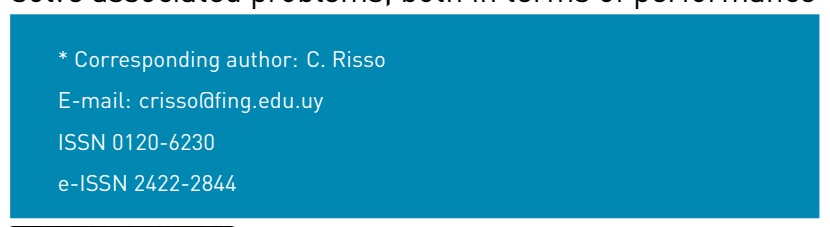

and error bounds. We added a selected set of solutions particulars, which provide insights of operational changes smart-grids allow.

The absence of fossil energy sources, such as oil, coal or gas, spurred decades ago Uruguayan authorities to invest in hydroelectric dams as its main source of electricity. Unlike fossil resources, the country accounted important hydraulic assets. Hence, Uruguay historically figured among top countries regarding the percentage of electricity coming from renewable sources. The national electric power matrix was complemented with 
conventional oil-fired thermal generation plants. Later on, the interconnection with its border neighbors (Argentina and Brazil) supplied an additional level of resilience and robustness to the system. As demand grew, the frequency at which thermal generation plants were used increased as well, so did the energy costs. Similar conditions were taking place in Argentina and Brazil, so importing electricity was as expensive as importing oil to keep thermal plants running. By 2007, the situation became critical and the national authorities started a process of diversification of the power sources, which aimed on biomass and wind power at early stages.

Today, Uruguay is a world leader in the usage of renewable energies, serving $96 \%$ of its own demand of electricity from renewable sources (see [2]). Table 1 presents the main details regarding units of the Uruguayan power plant by late 2017. The source is ADME (Administración Del Mercado Eléctrico) and it is available at http://adme.com.uy. The extremely low dependence upon fossil energies isolates the Uruguayan electricity market from commodities volatility. On the other hand, and as it counts in Table 1, over one third of the total energy consumed comes from wind-power, which is itself highly volatile in the short-term.

Table 1 Details of units in the installed power plant by type of energy source [source ADME:2017]

\begin{tabular}{lccccc}
\hline $\begin{array}{c}\text { Energy by } \\
\text { Type of Source }\end{array}$ & $\begin{array}{c}\text { Number of } \\
\text { Units }\end{array}$ & $\begin{array}{c}\text { Installed Power } \\
\text { Plant (MW) }\end{array}$ & $\begin{array}{c}\text { Relative } \\
\text { Subtotal }\end{array}$ & $\begin{array}{c}\text { Produced Energy } \\
\text { Total 2017 (GWh) }\end{array}$ & $\begin{array}{c}\text { Relative } \\
\text { Subtotal }\end{array}$ \\
\hline Biomass & 12 & 200 & $4.4 \%$ & 900 & $7.1 \%$ \\
Wind-power & 37 & 1.437 & $31.5 \%$ & 4.400 & $34.9 \%$ \\
Solar & 17 & 230 & $5 \%$ & 200 & $1.6 \%$ \\
\hline Hydroelectric & 4 & 1.534 & $33.7 \%$ & 6.200 & $49.2 \%$ \\
\hline Combined Cycle & 1 & 550 & $12.1 \%$ & 100 & $0.9 \%$ \\
Other Thermal Units & 4 & 604 & $13.3 \%$ & 800 & $6.3 \%$ \\
\hline
\end{tabular}

Managing the electric grid of a country is a challenging task that must be carried out carefully and optimally. In order to accomplish that, multiple problems are to be solved, spanning different scales of time and components. The main objects are: generating plants, the transmission and distribution networks. Long-term planning usually applies to assess the return of investments over those objects along many years ahead. Medium-term planning usually refers to the valuation of intangible resources, such as the height of the lake in an electric dam accounted as an economic asset. Short-term planning consists in crafting optimal dispatch schedules some days ahead, in order to efficiently coordinate the usage of available resources. Beyond that time scale, there are almost real-time models to keep the physical variables of the system (e.g. frequency, active and reactive power) under control. This work aims on the short-term power dispatch of the grid, whose outcome sets the prices of energy in the electricity market. Due to its short scale of time la few days ahead), such models can assume many sources of uncertainty as deterministic. For instance, oil prices can be considered as fixed along some days to follow, and although sudden/unexpected rains could arise, they hardly change the level of water reservoirs to a significant point.

The former premisses are actually quite realistic when applied to conventional and some non-conventional energy sources (e.g. biomass). Regarding wind and solar power however, those hypotheses become erroneous. The intrinsic stochastic nature of wind and solar power turns out the short-term dispatch of the grid into a much harder challenge, which is object of academic and industrial interest (see [3] and [4]). In its economical dimension, this volatility indicates that wind-energy constitutes a risk position. Variable renewable energies (VRE) have a negative impact in the operation costs of the system. The standard approach on systems coming from conventional sources (i.e. coal, atomic, etc.) consists in implementing redispatch measures, which aim on maintaining the energy balance of the overall system. Those situations where production of energy exceeds demand (i.e. congestions) are managed by ramping down portions of the controllable plant before the congestion, and ramping up the plant behind it. In fact, in most wholesale markets, managing congestion is sold and accounted separately as ramping services. Real-world examples (UK and Germany) of such problems are described in [5].

Under steady conditions lenergy prices, weather conditions, date of a yearl demand is highly predictable, so given a particular date of the year and an accurate weather forecast, the demand over the grid is among those variables that could be considered as known. This is due to low deviations associated with a large number of users under a stationary behaviour. As a consequence, legacy short-term optimal schedule models are deterministic, or deal with narrow variance in the variables. In addition, traditional instruments to modulate demand with economic measures go by setting different prices between hours on a day, intending to move a fraction of energy consumption from the demand's peak hour towards demand valleys (night-valley filling). Such instruments are based on the premisse that energy is scarce, while the truth is that non-conventional energies, especially wind-power, can either be lower or higher than forecasted.

Smart-grid technologies are a cornerstone for Smart-cities paradigm. Smart-grids allow coordinating important portions of the demand, which could now be headed in opposite direction to wind-power variations and accounted as a hedge instruments against generation risks (demand response). There are many ways to get benefits from demand control. For instance, works [6], [7] and [8] are inspired in a free-market environment, 
with a kind of underlying stock exchange where energy offers are traded. Sometimes this is not possible due to regulatory or scalability issues. Besides, wind and solar power fluctuate so rapidly, that implementing classical financial contracts (e.g. forwards or swaps) over a system with high penetration of non-conventional lthus highly volatile) results far from optimal.

Complementing previous references, [9] analyzes the overall economical contribution for a wholesale market of being able to control portions laround $10 \%$ in that studyl of the total demand. An Independent System Operator is assumed, which aims on minimizing total cost (maximizing social welfare). Two types of thermal storage assimilable to deferrable demand are considered; they are: Heating, Ventilation and Air Conditioning (HVAC) and electric Water Heating (WH). Results are econometric and derive from short-term economical simulations over New York and New England regions (NYNE). The reference installed plant is so that renewable sources (hydro mostly) add up to less than 10\%. Simulation instances extend power capacity with wind-power by $14 \%$, and concludes that HVAC and WH deferrable demands allow saving from $2 \%$ to $17 \%$, depending on the season, which sets requirements for Water Heating and Air Conditioning. Main differences with the work here presented are: an antagonistic composition of the installed plant (mostly renewable vs non-renewable); a lesser seasonal behavior in the Uruguayan case lpower winter-to-fall gap in Uruguay is 23\%, while spring-to-summer in NYNE's is $350 \%$ ); the absence of ramping services in the Uruguayan market.

Using batteries is another instrument to mitigate costs from ramping services. In [10], the authors simulate savings coming from having storage units in the Korean system as it is expected to be by 2029. Currently, most Korean electricity comes from coal and atomic sources. Wind-power and photovoltaic combined are below the $4 \%$ of the energy consumed. Government goal is to rise this figure to $30 \%$ by 2029 . The work concludes that batteries allow cost savings bellow $1 \%$, while combining wind-power and photovoltaic in an appropriate balance saves almost $10 \%$ of costs.

Against novel uncertainty in generation, smart-grids capabilities to manage demand and storage as a mean to improve dispatch efficiency show promising results and constitute an area of intensive research (see [11-13] and [14]). This document explores the benefits of using smart-grid technologies and residential energy storage, to coordinate part of demands with the uncertain offer of energy in the system. The application case is based on the particulars of the Uruguayan market, where only large-scale energy consumers are allowed to use the electricity market, while residential users only can get electricity from the state-owned company. In this wholesale electricity market, the price is not set by pairing bids and demands. Instead, production parameters of generators le.g. minimum and maximum power, fixed and variable costs) are public, and up from them, the authorities that operate the system dictate when and how much energy is going to be produced by each unit. This is why ramping services are not (explicitly) accounted in the Uruguayan market.

Production decisions are driven by a short-term reference optimization model, whose objective function aims on minimizing the total cost of generation. Such premisses are ideal for the approach presented in this work, which is stated from a short-term point of view optimization. Problem instances are based on real data of the Uruguayan market, chosen to be representative of different scenarios. It is worth mentioning that these results show how the existence of smart-grid technologies allows improving the efficiency of the system, not the return of the investments necessary to achieve such smart-grid grade.

The remaining of this document is organized as follows: Section 2 shows the short-term volatility of wind power and briefs about some techniques used to master it; Section 3 describes the main characteristics of the optimization models used to estimate the benefits of counting with smart-grid technologies; Section 4 presents the set of test scenarios used as instances of the previous models and numerical results; while Section 5 summarizes the main conclusions of this work and lines of future work.

\section{Wind power uncertainty}

This section shows how variable wind-power is, when described as a stochastic process, and it briefly presents some of the techniques used to likely fence its realizations. The historical of wind-power data in Uruguay has a few years, and along this period the installed power plant was firmly growing, so instead of expressing power in terms of MW we use the Plant Load Factor (PLF), which corresponds to the actual power generated at each time, divided by the sum of the installed power capacity of each wind turbine in the system at each moment. So, $0 \leq$ PLF $\leq 1$ for each hour. Hence, information is normalized, and we can disregard of changes in the installed capacity during the period of analysis.

Figure 1 shows the daily cumulated PLF (the sum of hourly PLFs, which then ranges from 0 to 24) along two consecutive years of summer days. We have selected days of one season to avoid deviations coming from seasonal behaviour. The figure shows how after a week or two, 

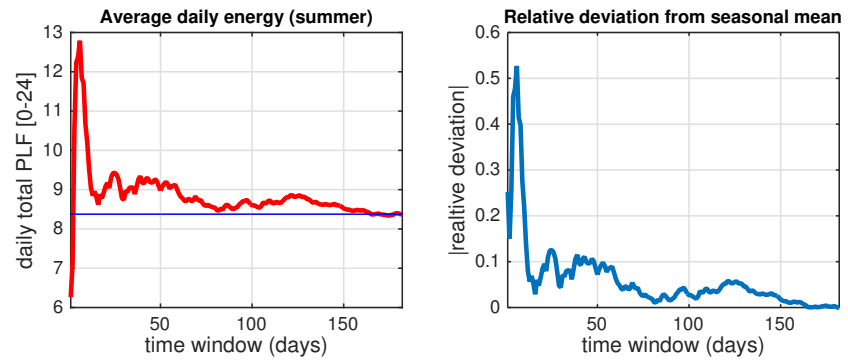

Figure 1 Time window average for daily wind energy on summer days over two years
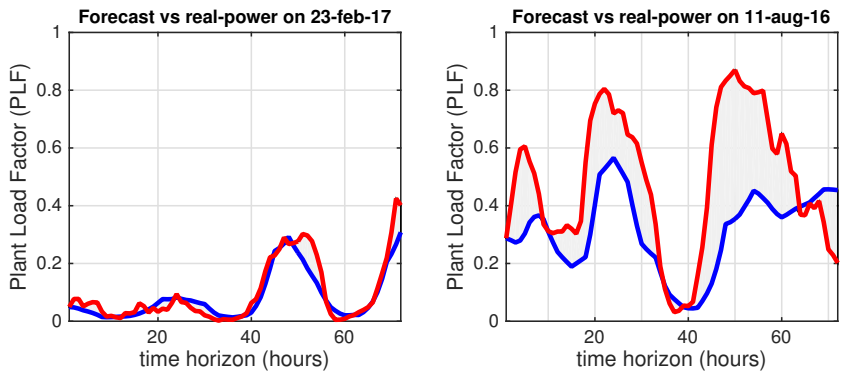

Figure 3 Examples of $72 \mathrm{hs}$ forecasts (blue) and the actual power registered (red)

the process goes inside the $10 \%$ error band, respect to the average value for that season.

Therefore, wind-power is fairly regular when used in medium-term planning. For shorter periods of time, the situation is quite the opposite. The leftmost of Figure 2 sketches the distribution of daily cumulated PLFs, while the rightmost part plots 120 actual daily realizations of the process (blue curves) along one year (i.e. 30\%), and the average PLF at each hour (black asterisks). Realizations were chosen by being those that are farthest from the average. We will not go further in the direction of standalone classical statistical descriptive, since it is seldom used.
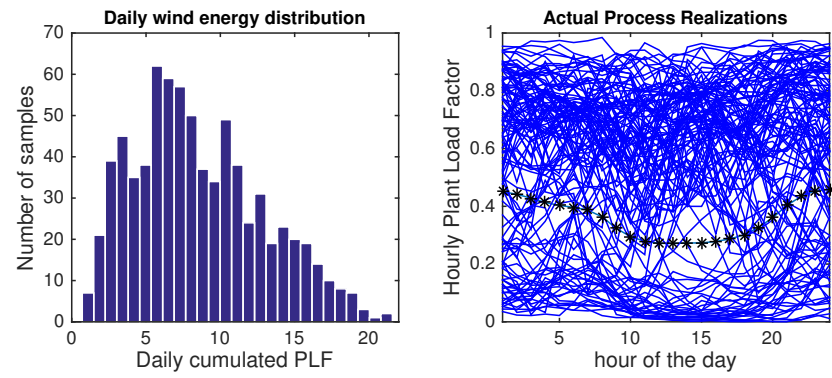

Figure 2 Histogram of daily wind energy samples [leftmost], and $30 \%$ most atypical realizations for Uruguayan wind-power over a year [rightmost]

Complementarily, there are approaches for short-term wind power forecasting based on numerical simulations of atmosphere's wind flows. For a couple of days ahead period, or even larger time windows, numerical simulations are usually more accurate than purely statistical models. Figure 3 presents $72 \mathrm{hs}$ ahead forecasts (blue curves) and actual power series (red curve) for two samples within the actual data-set. These and other historical series are available at: http://www.ute.com. uy/SgePublico/ConsPrevGeneracioEolica.aspx.

Although in order to follow the process whereabouts at early stages, numerical simulations perform better than purely statistical methods, they are far from being trustworthy in what respects to the construction of likely scenarios at larger periods. The plot over the rightmost of Figure 3 is an example where the difference of energy between a forecast and the actual processes (i.e. the grey areal, accounts $57 \%$ of the average PLF for the period.

Among other points, this work benchmarks the performance of deterministic vs stochastic optimization models over the same test scenarios. As we see later on, the additional accuracy of stochastic version improves the figures for assessing potential savings coming from using smart-grids. Therefore, reliable energy-bands were used to fence wind-power process with a high degree of energy certainty. Those bands were crafted up from the combination of three independent sets of forecasts and the correspondent actual power series. As an example, Figure 4 shows the confidence band for a particular day within the test-set. Bands were calibrated seeking for the average off-band energy (i.e. green areas in the figure) to be below $10 \%$ of the average PLF. Besides, bands are adjusted so less than $10 \%$ of the days violate the previous condition. The calibration whose average band width is minimal while fulfills the previous conditions, has an average width deviation respect to the centroid (i.e. blue curve) slightly above $10 \%$ of the average energy demand (the fact this final figure replicates the previous is just a coincide). The details of the technique used to craft these bands are documented in [15].

\section{Short-term optimization models}

This section describes the main entities of the Uruguayan electricity market and examples about how some of them are modeled. The section also elaborates about how they are assembled into a single optimization model.

Over the upmost part of Figure 5 is represented the power offer of the system. Renewable (green) energies comprise: wind and solar power (non-cumulative renewable / NCR), Hydroelectricity (HYD) and Biomass, whose units are basically thermal generation plants (TER). The installed power plant is completed with standard fossil thermal generation units. Upon the rightmost-bottom of Figure 5 non-manageable demands are represented. They 


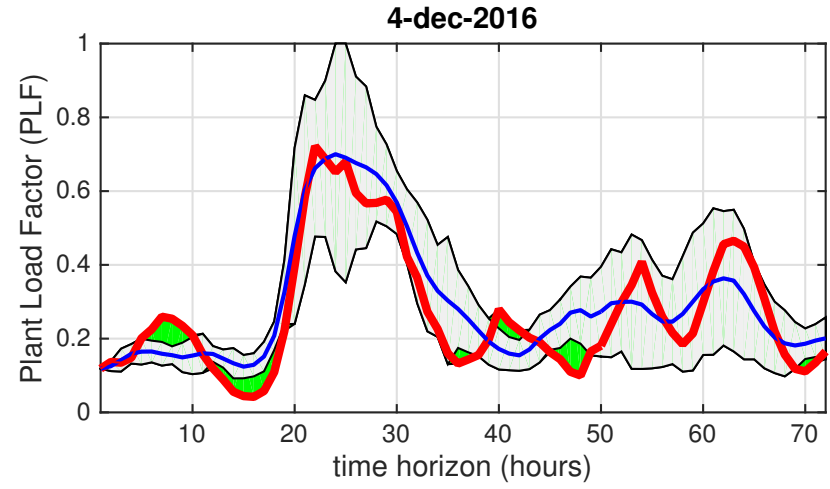

Figure 4 A confidence band (grey) crafted after three forecasts, its centroid (blue), the actual process (red), and the off-band energy (green)

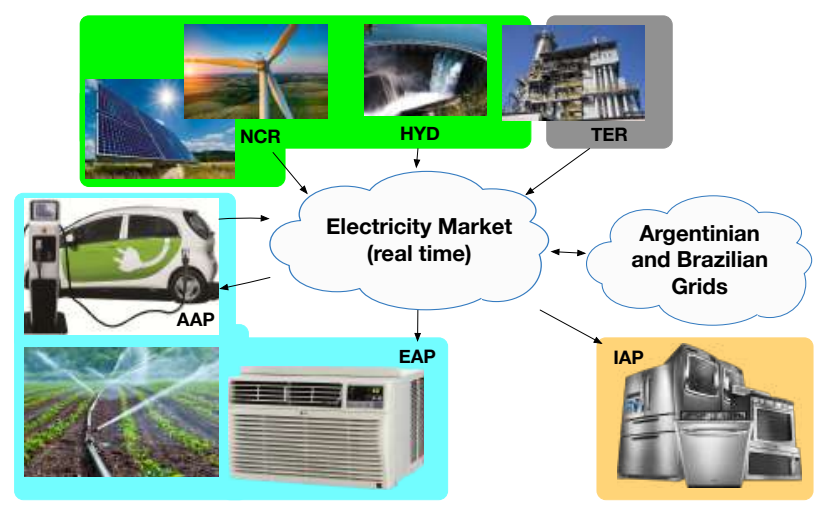

Figure 5 Entities of the wholesale electricity market

are typically associated (though not limited) to some residential appliances. Such inelastic appliances (IAP) are considered hourly predictable demands over the time horizon to optimize, which is $72 \mathrm{hs}$ ahead in this work (i.e. the time horizon of wind-power forecasts). In other words, inelastic appliances impose a power requirement to the system. Variants of the basic model introduce: elastic applications (EAP) or active applications (AAP). Elastic applications are those where requirements are better expressed in terms of energy rather than power. They impose some instant power constraints, but the idea is that substantial portions of the required energy within certain time windows could be either deferred or advanced into that window. Finally, in addition to being elastic, active applications can return power to the grid when necessary.

In all the models explored in this work, elastic and active applications are at the service of the system (i.e. social-welfare). We assume they can be remotely controlled, so as long as basic power requirements are fulfilled, the gaps of energy to complete those demands constitute control variables just as those of the installed power plant, and they are also used to get the most of the optimization. This is a subtle but fundamental difference with approaches as [9] or [10], which are econometric models based upon historical costs. The model here presented pursues cost savings, but it is founded upon technical constraints (commitment times, operational limits, temporal dependence among variables, etc.), so it is more realistic from the operational perspective.

\subsection{Rapid thermal units}

Each entity has a reference mixed-integer optimization sub-model or block. All these blocks combined and instantiated for a particular data-set define the whole optimization problem for that instance and variant. For example, Equation (1) is the framework to model simple thermal plants, labeled as Other Thermal Units in Table 1.

$\begin{cases}\min _{x_{t}^{g}, y_{t}^{g}, w_{t}^{g}} a \sum_{t \in T} x_{t}^{g}+b \sum_{t \in T} w_{t}^{g}+\alpha \sum_{t \in T} y_{t}^{g} & \\ m_{G T} \cdot x_{t}^{g} \leq w_{t}^{g}, & t \in T \\ w_{t}^{g} \leq M_{G T} \cdot x_{t}^{g}, & t \in T \\ y_{t}^{g} \geq x_{t}^{g}-x_{t-1}^{g}, & t \in T \\ 2 x_{t}^{g}-2 x_{t+1}^{g}+x_{t+2}^{g}+x_{t+3}^{g} \geq 0, & t=1, ., T_{m}-3 \\ 2 x_{t}^{g}-2 x_{t+1}^{g}+x_{t+2}^{g}+x_{t+3}^{g} \leq 2, & t=1, ., T_{m}-3 \\ x_{t}^{g}, y_{t}^{g} \in\{0,1\} & \end{cases}$

Boolean variables $x_{t}^{g}$ indicate whether the unit $g$ is active or not at the time moment $t$. The period of activation of a small thermal unit is less than $10 \mathrm{~min}$, so it can be considered instantaneous for a time slot of one hour. Whenever active $\left(x_{t}^{g}=1\right)$ the power generated by each unit $\left(w_{t}^{g}\right)$ must be between technical minimum $\left(m_{G T}\right)$ and maximum $\left(M_{G T}\right)$ values. This is imposed with constraints $(i)$ and $(i i)$. Boolean variables $y_{t}^{g}$ identify the instants of time $t$ at which a unit $g$ is activated, which is forced by constraint (iii).

The terms in the objective function respectively correspond to: the hourly fixed cost of operation when the unit is active; the variable cost incurred by the level of power generated; and the operational costs incurred in by activating the unit, i.e., fuel expenditures for warming up the unit plus a maintenance share per operation cycles.

Besides of being costly in terms of maintenance, the process of frequently activating thermal units is not operationally friendly. Recall that under other regulations, this kind of rapid units can be sold as ramping services, with a discretionary cost. In the Uruguayan context, we must include precise technical particulars. Therefore, as an example, we added constraints to guarantee that once started, a unit should be active (for instance) at least 3 hours (constraints $(i v)$ ), and also to force it to be inactive for at least 3 hours after stopped (constraints $(v)$ I. These constraints should be complemented with boundary conditions when the initial or final activity states are inherited as part of the instance. 
Table 2 Parameters for simple thermal units

\begin{tabular}{lcrrrr}
\hline $\begin{array}{l}\text { Name of each } \\
\text { Thermal Unit }\end{array}$ & $\begin{array}{c}\text { Number of } \\
\text { power subunits }\end{array}$ & $\begin{array}{c}\text { Power } \\
\min \end{array}$ & $\begin{array}{c}\text { (MW) } \\
\max \end{array}$ & $\begin{array}{c}\mathrm{a} \\
\text { USD }\end{array}$ & $\begin{array}{c}\mathrm{b} \\
\text { USD }\end{array}$ \\
\hline Central Batlle (Motores) & 6 & 6 & 60 & 0 & 82 \\
Punta del Tigre: 1 to 6 & 6 & 90 & 288 & 7423 & 86 \\
Punta del Tigre: 7 and 8 & 2 & 0.6 & 48 & 1619 & 88 \\
Central Térmica Respaldo & 2 & 40 & 208 & 6819 & 103 \\
\hline
\end{tabular}

Table 2 shows a possible set of parameters for those simple thermal units, for a particular oil price during 2016. We could not find public data to valuate $\alpha$.

\subsection{Units with complex commitments}

Unlike simple thermal units, the Combined Cycle Plant (or CCP) has slow time commitments, of around four hours till full-operation, so its start-up details should be integrated into the model. Reference parameters are: $m_{G T}=58 \mathrm{MW}, M_{G T}=550 \mathrm{MW}, a=5240 \mathrm{USD}$ (hourly fixed cost), $b=63 \mathrm{USD} / \mathrm{MW}$ (variable cost) and $\alpha=5500$ USD. Along the four hours it takes the CCP to attain its full-operation, the plant gradually increases the output power following a predetermine ramp. During that ramp-up, the efficiency is lower, so $b$ is $35 \%$ higher and we use two variable costs: $b_{c c}=b b_{r a}=1.35 b$. Figure 6 sketches the production curve, that is, the power-vs-time curve the CCP has to follow before achieving its technical maximum.

To model such type of unit we used four types of variables and over twenty types of constraints. Equation (2) corresponds to a relaxation of the whole problem. Variables $x_{t}$, and $w_{t}$ are homologous to (1), although in this case we differentiate power produced over the ramp $\left(w_{t}^{r a}\right)$, with that delivered at full-operation $\left(w_{t}^{c c}\right)$. Variables $x_{t}$ indicate whether the CCP is fully operative $\left(x_{t}=1\right)$ or not, while $y_{t}=1$ marks that the unit at the instant $t$ is in a stair of the starting power ramp.

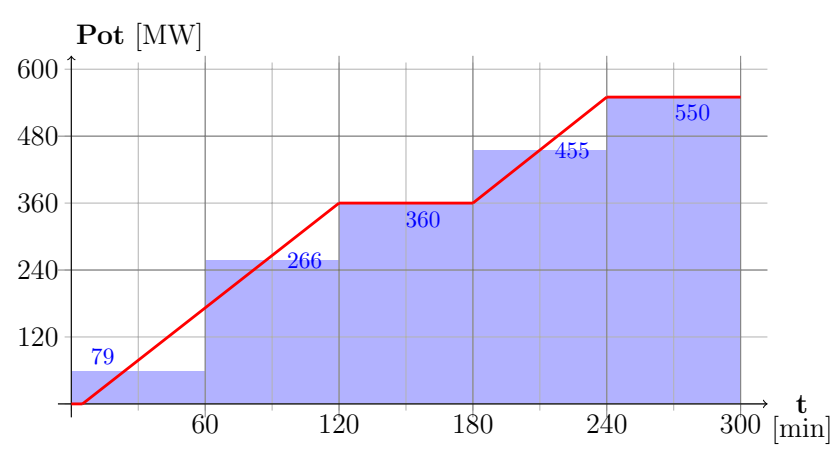

Figure 6 Power evolution over time to reach technical maximum $\left(M_{G T}\right)$, and the corresponding sequence of stairs

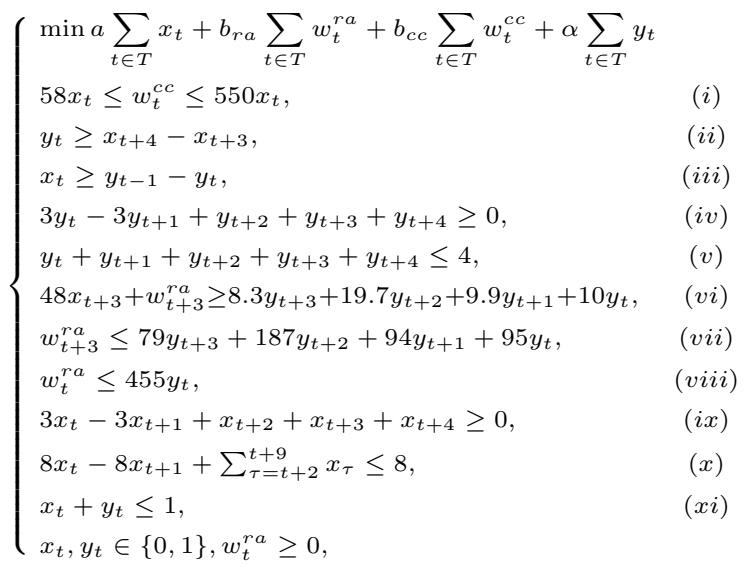

A curious fact is that the CCP power stairs sequence lasts 4hours, independently of the target power. The values of the sequence on the other hand, must adjust proportionally to the aimed power. The following is an example of values to be taken by variables when the CCP is required to be fully operative by $t$ and producing 440MW at that time.

\begin{tabular}{c|c|c|c|c|c|c|c} 
& $\mathrm{t}-\mathbf{5}$ & $\mathrm{t}-\mathbf{4}$ & $\mathrm{t}-\mathbf{3}$ & $\mathrm{t}-\mathbf{2}$ & $\mathrm{t}-\mathbf{1}$ & $\mathrm{t}$ & $\mathrm{t}+\mathbf{1}$ \\
\hline $\mathrm{x}_{\mathrm{t}}$ & 0 & 0 & 0 & 0 & 0 & 1 & 1 \\
\hline $\mathrm{y}_{\mathrm{t}}$ & 0 & 1 & 1 & 1 & 1 & 0 & 0 \\
\hline $\mathrm{w}_{\mathrm{t}}^{\mathrm{ra}}$ & 0 & 63.2 & 212.8 & 288 & 364 & 0 & 0 \\
\hline $\mathrm{w}_{\mathrm{t}}^{\mathrm{c}}$ & 0 & 0 & 0 & 0 & 0 & 440 & 480
\end{tabular}

Constraints $(i)$ in (2) bound the technical power limits. Group (ii) forces a ramp to be started $t-4$ hours before entering into full-operation, while (iii) forces the CCP to start full-operation after a ramp is finished. Constraints $(i v)$ and $(v)$ combined impose the ramp to last exactly 4 hours. Constraints (vi) to (viii) ensure power production to be between lower and upper stairs limits during the ramp-up. The resulting $w_{t}^{r a}$ does not have to follow the exact sequence (as in the previous example), so (2) is actually a relaxation from which $y$ 's values are taken for a second (re-feasibilization) stage, not shown here. Once in full operation condition, the CCP should not be stopped until four hours later (i.e. eight hours since started), and once stopped there should be a period of at least 6 hours until start it up again. That is imposed through constraints $(i x)$ and $(x)$. Finally, constraints $(x i)$ yield to mutual exclusion between ramp and full-operation stages. CCP is the most efficient among the thermal units. However, it is not always chosen by the optimization process because of its complex commitment times, which sometimes does not fit system needs.

\subsection{Hydroelectric}

A third of the installed power plant and a half of the energy produced in Uruguay still come from hydroelectricity. 
Hydroelectric dams are geographically distributed over the mid-north of the country, as sketched in Figure 7. Three of them are in tandem along an internal river (Río Negro), while the fourth -placed over the Uruguay River- is a binational joint project with Argentina.

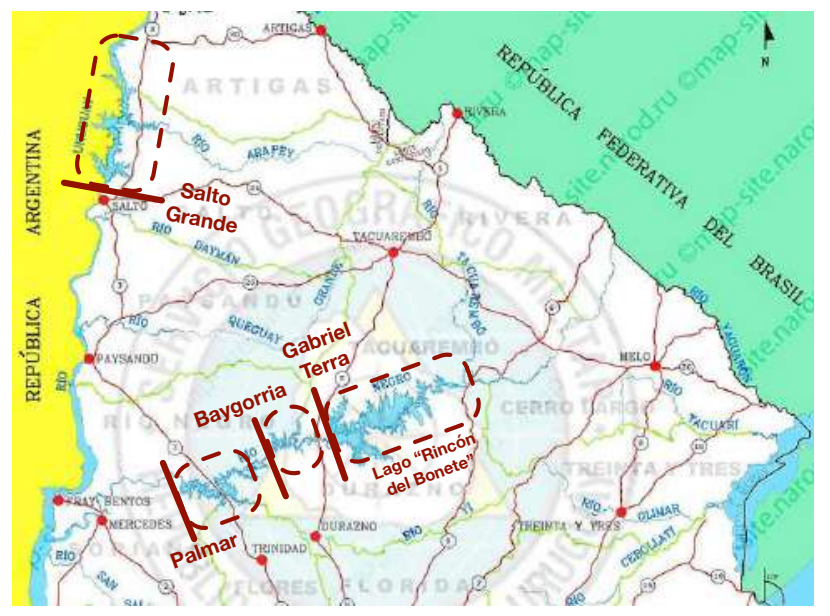

Figure 7 Geographical distribution of hydroelectric dams in Uruguay

The main state variable of a hydroelectric dam is the volume of water in its storage lake. That volume determines the head (i.e., the height difference between the surface of the reservoir and the turbines). Control variables regard with how much water flows through the turbines, and how much is spilled.

The higher the head, the most energy obtained by volume of water turbinated. Actually, this also depends on the level the river after the dam, which in Uruguayan low steep river courses is highly dependent on the total flow itself (i.e. turbinated plus spilled), so the production function is far from being linear.

Natural influxes into the reservoir increase the volume of water in it, while turbinated water decreases it. Intuition suggests that production efficiency passes by keeping the head as high as possible, while waters flow turbines downwards. However, whenever the head surpasses a security threshold, water must be spilled.

Spilling not only wastes the resource, but, as mentioned before, increases the level downstream, what reduces the efficiency for the fraction of water really passing through the turbines.

As it counts in Table 3 and can be observed in Figure 7, the sequence of dams over the Río Negro binds influxes of some dams with the outflux of the previous. Table 3 also shows the emptying time when the unit is used at its maximum power. Within an optimization horizon of three days, control decisions hardly affect the efficiency (head or
Table 3 Parameters of the hydroelectric units in the Uruguayan power plant

\begin{tabular}{|c|c|c|c|}
\hline $\begin{array}{l}\text { Hydroelectric } \\
\text { power plant }\end{array}$ & $\begin{array}{l}\text { Power } \\
\text { (MW) }\end{array}$ & $\begin{array}{l}\text { Empty } \\
\text { (days) }\end{array}$ & $\begin{array}{l}\text { Influxes } \\
\text { Coming From }\end{array}$ \\
\hline Rincón del Bonete & 148 & $140 d$ & Río Negro \\
\hline Baygorria & 108 & $1 d$ & Bonete's outflux 6hs earlier \\
\hline Palmar & 333 & $14 d$ & Yí river and Baygorria $10 \mathrm{hs}$ earlier \\
\hline Salto Grande & $(2 x) 945$ & $15 d$ & Uruguay river \\
\hline
\end{tabular}

spilling) in Bonete, Palmar or Salto. Baygorria on the other hand must be finely tuned. In order to get to an integer linear programing model, we used artificial variables and a linear piecewise approximation for the production curve. Besides, the lake's geometry was assumed cylindrical for simplicity. Elaborating into those details would deviate the focus of this document, so they were intentionally left outside of the scope.

Temporal outfluxes/influxes dependance and non-linearity aside, hydroelectric units do not have complex commitments as those of the CCP.

\subsection{Storage batteries}

Units of energy storage are modeled in Equation (3) without an objective function, i.e., without a direct profit. So they are at the service of the system.

$$
\left\{\begin{array}{l}
b_{t}=b_{0}+\delta \sum_{\tau=1}^{\tau=t} r_{\tau}^{c}-\sum_{\tau=1}^{\tau=t} r_{\tau}^{d} \\
0 \leq r_{t}^{c} \leq \overline{r_{c}} \\
0 \leq r_{t}^{d} \leq \overline{r_{d}} \\
0 \leq b_{t} \leq \bar{b}
\end{array}\right.
$$

The state variable $b_{t}$ indicates the level of charge of the battery, i.e., the energy cumulated in it at time $t$. Control variables $r_{t}^{c}$ and $r_{t}^{d}$ indicate how much power is used at time $t$ to respectively charge or discharge the battery. In the first case the power is taken from the grid las a demand), while in the second is returned (as generation). There are upper limits for control and state variables. The parameter $\delta<1$ represents the inefficiency (loss of power) of charge/discharge cycles. There are no storage units in the Uruguayan grid, so as a reference, we used parameters as in a real-world project ("Neoen \& Tesla Motors" in Australia). They are: $\overline{r_{c}}=35 \mathrm{MW}, \overline{r_{d}}=100 \mathrm{MW}, \bar{b}=$ $140 \mathrm{MWh}$ y $\delta=0.9$.

\subsection{Demands}

Demands are the entities that bind all sub-problems into one. When demands are hourly determined, they form part of the data-set of the instance and are integrated into problem as set of $T$ constraints: $\sum_{g \in G} w_{t}^{g} \geq d_{t}$. 
$t \in T$. Being $T$ the number of hours along which we are optimizing, $d_{t}$ the expected demand at the hour $t, G$ the set of generation units and $w_{t}^{g}$ the power produced by the unit $g$ at time $t$ (plus storage's uncharging when available). In more general terms, consider an application $j$ in a set of applications $J$, and $A^{j}$ a set of $c_{j}$ disjoint time intervals $A^{j}=\left\{A_{1}^{j}, \ldots, A_{c_{j}}^{j}\right\}$ proper of that application. Let $D_{p}^{j}$ be the energy requirement of the application $j$ along the $p^{\text {th }}$ interval $\left(1 \leq p \leq c_{j}\right.$ ), and consider the control variable $z_{t}^{j}$, the power supplied by the grid to fulfill demand $j$ at hour $t$. Besides, let $\underline{z}_{t}^{j}$ and $\bar{z}_{t}^{j}$ respectively be the lower and upper power bounds. Expressed so, an elastic demand is satisfied whenever constraints in Equation (4) are satisfied.

$$
\left\{\begin{array}{l}
\sum_{t \in A_{p}^{j}} z_{t}^{j} \geq D_{p}^{j}, \quad 1 \leq p \leq c_{j}, j \in J \\
\underline{z}_{t}^{j} \leq z_{t}^{j} \leq \bar{z}_{t}^{j} \quad \forall t
\end{array}\right.
$$

The new power balance condition is $\sum_{g \in G} w_{t}^{g} \geq \sum_{j \in J} z_{t}^{j}$, for every $t \in T$.

Observe that traditional (hourly fixed) demands can be easily expressed using $A=\{1, \cdots, T\}$ and setting $D_{t}=d_{t}$. In this document, we derive two flavors from this general model for demands. One of them is the traditional, where there is only one kind of demand, whose hourly requirements are known. In the other, we assume that $30 \%$ of the residential demand is elastic within each day.

Almost $52 \%$ of the total energy in Uruguay is dispatched for residential use. Therefore, power demand is first disaggregated between residential $\left(d_{t}^{R}\right)$ and large scale energy consumers $\left(d_{t}^{L}\right)$. Next, we set $\underline{z}_{t}=0.7 d_{t}^{R}+d_{t}^{L}$, $\bar{z}_{t}=\infty, A=\left\{A_{1}, A_{2}, A_{3}\right\}$ where $\bar{A}_{1}=\{1, \ldots, 24\}$, $A_{2}=\{25, \ldots, 48\}$ and $A_{3}=\{49, \ldots, 72\}$. Finally, we assign $D_{1}=\sum_{t=1}^{24} 0.3 d_{t}^{R}, D_{2}=\sum_{t=25}^{48} 0.3 d_{t}^{R}$ and $D_{3}=\sum_{t=49}^{72} 0.3 d_{t}^{R}$.

\subsection{Mathematical models}

Although the optimization subproblems previously reported correctly describe components by separate, there is more than one choice to combine them into a whole Mixed-Integer Optimization Problem (MIP).

Aligned with the purpose of this work, we chose two dimensions to branch MIP flavors, with two variants each, so the number of MIP versions totalizes four. Parameters apart, the demand's elasticity itself is a characteristic of primordial importance. When demands are hourly determined (inelastic), we simply used constraints $\sum_{g \in G} w_{t}^{g} \geq d_{t}$ to bind all blocks into a single MIP, because this approach is numerically much simpler and more efficient. Constraints and variables as in (3) and (4) are only included when controllable demands are effectively available, that is, demands' controllability and storage are always paired.

Non-conventional energies' volatility is another key aspect of interest to this work. There are many approaches to integrate uncertainty into an optimization problem. A simple one goes by optimizing upon the average, which is basically assuming deterministic behavior. More accurate approaches are explicitly stochastic but they require to deal with a higher number of variables. Thus, in addition to opening models by demand elasticity, we branch them by using deterministic or stochastic versions of the problem.

Stochastic versions use the classic stochastic programming framework (see [4]) with four stages in this case. Time intervals (in hours) for each stage respectively are: 1-6, 7-24, 25-48 and 49-72. There is only one scenario for stage 1 . Stages 2 to 4 open into 3 scenarios each, so the total number of leaves in the scenarios tree is 27. As we see in the following section, these stages are aligned with wind-power particulars.

It is a fact the existence of electrical networks among generation plants and consumers, which add constraints that could degrade solution's optimality. This work disregards constraints of such components.

\section{Experimental results}

Since solar power was incipient by the time this work was being developed, we only consider uncertainties coming from wind-power. In every case, confidence bands (see Figure 4) are used to bound process realizations. Deterministic versions assume the wind power will be as the centroid of the band (blue curve in Figure 4), which is simpler but potentially inaccurate.

Assuming a power assimilation preprocessing, forecasts are proven accurate during the first six hours (see [16]], so we can model stage-1 as deterministic. For the rest of the stages, trajectories are built to explore the confidence bands in order to reproduce different realizations. We use trajectories that combine: lower, mid and upper wind-power expectations, then, stochastic programming versions of the problems use 27 trajectories. The procedure for crafting trajectories includes an interpolation process upon boundaries between stages. That final processing conveys a more realistic behavior for transitions between low-to-high or high-to-low levels of wind-power, without which, power curves would lose their natural continuity. The probability of each trajectory is estimated up from historical forecast vs actual power records. 
Along this section we identify representative scenarios, which are defined by combining the state of hydro-resources with wind-power expectations. As it counts in Section 3.6, for each representative scenario four versions of the problem are solved.

Historical data about actual dispatch is not available (they are considered confidential by authorities). However, since historical information for the real wind-power is available, we tested the convenience of every optimal schedule crafted, by comparing it with results of simulations of the real cost the system would have incurred in by using that plan as a guide.

\subsection{Optimization tools}

No optimization algorithm was developed to tackle down problem instances analyzed during this work. All of them were solved using a generic comercial Mixed Integer Optimizer: IBM(R) ILOG(R) CPLEX(R) Interactive Optimizer 12.6.3.0, on an HP ProLiant DL385 G7 server with $24 A M D$ Opteron(tm) 6172 processors, 72GB of DDR3 RAM and running CentOS 6.10 Linux operating system.

Running times registered over the whole set of cases studied (80 instances) in this work ranged from 1 to 320 seconds, which we found plenty acceptable.

Recall that (2) is actually a relaxation used to set CCP ramp-up instants. There is always a a-posteriori re-feasibilization stage, a computationally much simpler optimization, due to the lower number of integer variables. Thus, regardless of the version of the problem, the whole optimization is completed after two sub-optimizations (aka. iterations).

Simplest versions of the problem li.e. deterministic with inelastic demands) presented sub-second running times to find optimal solutions on both iterations. Besides, the gap between both objective's values was under $0.5 \%$. The last figure is the difference between a feasible solution (i.e. the outcome of the second iteration) and the optimal solution of a relaxation of the problem (i.e. first iteration), therefore it constitutes a bound of the error introduced by our approach for modeling the CCP after two iterations.

For those more complex versions li.e. stochastic with elastic demands and storage) a time-out of 300 s was set to CPLEX prior to run it for the first iteration. In all cases the solver exited by achieving that time-out, but always after finding feasible solutions with error bounds -estimated from the dual-primal gap- below $0.6 \%$. Running time till finding optimal solutions over second iterations in "stochastic + elastic demands + storage" versions were always below 20 seconds.
As a final comment, we note that both the "CPLEX execution times" (slightly above 5 minutes) and the errors that arise from Optimization plus Modeling were up to our initial expectations for this work.

\subsection{Problem instances}

Instances were defined up from scenarios particularly interesting to analyze sensibility against some key aspect the problem. Due to the importance of hydroelectric energy for the country, the availability of hydraulic resources is one the dimensions to explore. We defined five hydro-scenarios to test, they are as follows. HB1 is the historically-typical/statistically-representative scenario, with a good head of water in reservoirs and high expectations of new influxes over the next weeks to come. $\mathrm{SH} 1$ assumes a drought condition, with medium resources in the reservoirs and poor expectations about the new influxes. $\mathrm{SH} 2$ is a worse drought condition than in $\mathrm{SH} 1$, since now the head level in reservoirs is critical. EHT1 is an intermediate situation to HB1 and SH1. Resources are good but important new influxes are unlikely, so the valuation of the water (that comes from mid-term planning models) pushes prices towards those of fossil fuels. The valuation gives lowest prices for those reservoirs over Río Negro. EHT2 is similar to EHT1, but now Salto Grande reservoir has lower prices than those of Río Negro. Although not representative regarding the typical volume of rains in a year, SH1, SH2, EHT1 and EHT2 are important to stress the model.

The second dimension for scenarios is defined by the second power source by importance: the power-wind, which is also the main source of short-term uncertainty. We selected four "forecasts+actual power" among the set of historical series. Days in Figure 8 were chosen because they are typical, i.e., they are close to the medians of: off-band error, effective wind-power produced, and width of their confidence band. Hence, $4^{\text {th }}$ and $17^{\text {th }}$ December 2016 are statistically representative. Days in Figure 9 on
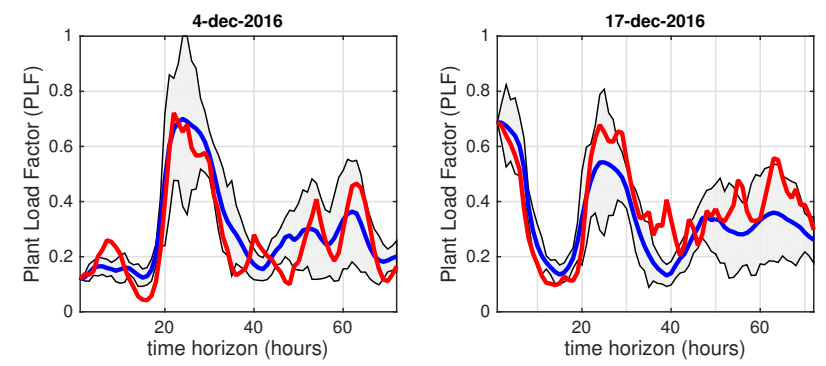

Figure 8 Representative wind-power samples

the other hand were chosen to stress the model. The leftmost sample for having the confidence band with the largest width, and the rightmost one for being among the 
samples with the higher off-band energy, i.e., for being among those bands with the poorest performance.
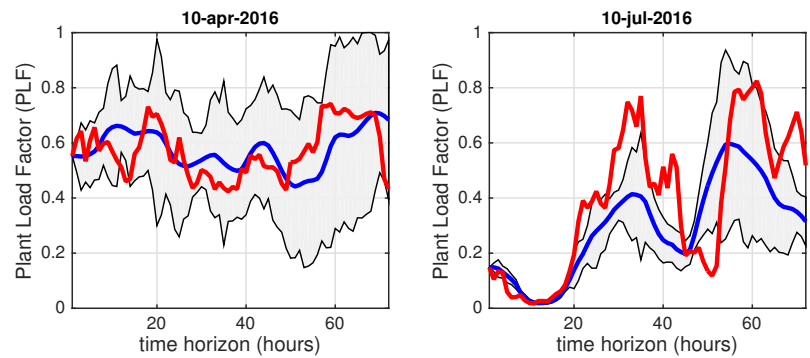

Figure 9 Stressing samples regarding forecast and wind-power series

In addition, the last sample has a particularity regarding power. Observe that in the period between the hour 51 and 54 rises almost $70 \%$ of the PLF, which rounds $1 \mathrm{GW}$, close to the average power consumption of the country.

\subsection{Numerical results}

In total, 80 problems are solved to explore those scenarios over different models $(4$ models $\times 5$ hydro-scenarios $\times 4$ wind-scenarios). In the first place, we show the results for the deterministic models over all hydro and wind scenarios. Results are presented in Table 4 (for hydro HB1 scenario), Table 5 (for EHT1 and EHT1 scenarios), and Table 6 (for SH1 and SH2).

Table 4 Cost [USD] deterministic optimization $72 \mathrm{hs}$ ahead. [hydro-scenario HB1]

\begin{tabular}{c|cccc}
\hline & 4-dec & 17-dec & 10-apr & 10-jul \\
\cline { 2 - 5 } Inelastic Demand & 348,930 & 334,760 & 241,230 & 359,730 \\
Elastic Demand & 327,200 & 311,240 & 239,350 & 344,780 \\
\hline
\end{tabular}

Complementing the gross information of Table 4, Table 5 and Table 6, we must add that after simulating the system dispatch using actual wind-power values, the absolute difference between the projected schedule and the simulation of the operation was between $3 \%$ and $6 \%$. Those differences correspond to error margins between a-priori dispatch plans and a-posteriori actual figures. Instances for hydro-scenario HB1 do not require the usage of thermal generation. This fact explains the low production costs. Conversely, several thermal units are to be activated in hydro-deficient scenarios EHT1, EHT2, SH1 and $\mathrm{SH}$, pushing up costs over the order of magnitude.

Observe that although costs and other conditions are similar, the system manages much more efficiently hydro-scenarios ETH2 than their homologous in EHT1, whose figures are similar to those of $\mathrm{SH} 1$ and $\mathrm{SH} 2$. Regardless of the hydro-scenario or demand elasticity, Apr/10/2016 always gets the lowest cost, with reductions in
Table 5 Cost [thousands of USD] deterministic optimization 72hs ahead [scenarios EHT1, EHT2]

\begin{tabular}{l|cccc}
\hline \multirow{3}{*}{$\begin{array}{l}\text { Inelastic Demand } \\
\text { Elastic Demand }\end{array}$} & \multicolumn{4}{|c}{ EHT1 } \\
\cline { 2 - 5 } & 4-dec & 17-dec & $\mathbf{1 0 - a p r}$ & $\mathbf{1 0 - j u l}$ \\
\cline { 2 - 5 } & 5,281 & 5,120 & 3,737 & 5,448 \\
& \multicolumn{4}{|c}{ EHT2 } \\
\cline { 2 - 5 } Inelastic Demand & 4-dec & $\mathbf{1 7 - d e c}$ & $\mathbf{1 0}$-apr & $\mathbf{1 0 - j u l}$ \\
\cline { 2 - 5 } Elastic Demand & 4,091 & 3,869 & 2,850 & 4,126 \\
\hline
\end{tabular}

Table 6 Cost [thousands of USD] deterministic optimization $72 \mathrm{hs}$ ahead [scenarios SH1, SH2]

\begin{tabular}{l|cccc}
\hline \multirow{3}{*}{$\begin{array}{l}\text { Inelastic Demand } \\
\text { Elastic Demand }\end{array}$} & \multicolumn{4}{|c}{ SH1 } \\
\cline { 2 - 5 } & 4-dec & 17-dec & 10-apr & 10-jul \\
\cline { 2 - 5 } & 5,696 & 5,419 & 3,857 & 5,731 \\
& \multicolumn{4}{|c}{ SH2 } \\
\cline { 2 - 5 } & 4-dec & 17-dec & 10-apr & 10-jul \\
\cline { 2 - 5 } Inelastic Demand & 5,706 & 5,428 & 3,857 & 5,742 \\
Elastic Demand & 5,621 & 5,337 & 3,735 & 5,646 \\
\hline
\end{tabular}

the order of $30 \%$. That date corresponds with an atypical scenario of "three windy days in a row", and evinces how sensible the system cost is to the power coming from wind farms.

Table 7 Relative deviation stochastic vs deterministic models [hydro-scenario HB1]

\begin{tabular}{l|rrrr}
\hline & 4-dec & 17-dec & 10-apr & 10-jul \\
\cline { 2 - 5 } Inelastic Demand & $-0.01 \%$ & $-0.24 \%$ & $-0.12 \%$ & $-0.09 \%$ \\
Elastic Demand & $0.18 \%$ & $-0.01 \%$ & $-1.00 \%$ & $-0.21 \%$ \\
\hline
\end{tabular}

Focusing now on the expected cost for stochastic versions, the values are quite similar to their corresponding deterministic instance, so Table 7, Table 8 and Table 9 present the relative difference with respect to figures in Table 4, Table 5 and Table 6, rather than absolute figures.

Table 8 Relative deviation stochastic vs deterministic models [hydro-scenarios EHT1, EHT2]

\begin{tabular}{|c|c|c|c|c|}
\hline \multirow{4}{*}{$\begin{array}{l}\text { Inelastic Demand } \\
\text { Elastic Demand }\end{array}$} & \multicolumn{4}{|c|}{ EHT1 } \\
\hline & 4-dec & 17-dec & 10-apr & 10-jul \\
\hline & $-0.28 \%$ & $-0.29 \%$ & $-0.19 \%$ & $-0.13 \%$ \\
\hline & $-0.42 \%$ & $-0.41 \%$ & $-0.36 \%$ & $-0.10 \%$ \\
\hline \multirow{4}{*}{$\begin{array}{l}\text { Inelastic Demand } \\
\text { Elastic Demand }\end{array}$} & \multicolumn{4}{|c|}{ EHT2 } \\
\hline & 4-dec & 17-dec & 10-apr & 10-jul \\
\hline & $-0.45 \%$ & $-0.21 \%$ & $-1.41 \%$ & $-0.30 \%$ \\
\hline & $-0.44 \%$ & $-0.34 \%$ & $-0.25 \%$ & $-0.14 \%$ \\
\hline
\end{tabular}

Observe that in 36 out of 40 instances, the stochastic version gets schedules with lower expected values than those of the deterministic version. This fact by itself is not relevant, however, after running a-posteriori simulations to assess models' robustness, we also found that differences between projected schedules and simulations 
Table 9 Relative deviation stochastic vs deterministic models [hydro-scenarios SH1, SH2]

\begin{tabular}{l|cccc}
\hline & \multicolumn{4}{|c}{ SH1 } \\
\cline { 2 - 5 } Inelastic Demand & 4-dec & $\mathbf{1 7 - d e c}$ & $\mathbf{1 0 - a p r}$ & $\mathbf{1 0 - j u l}$ \\
\cline { 2 - 5 } Elastic Demand & $-0.34 \%$ & $-0.33 \%$ & $-0.04 \%$ & $-0.09 \%$ \\
& $-0.51 \%$ & $-0.45 \%$ & $0.05 \%$ & $-0.02 \%$ \\
\hline \multirow{4}{*}{ Inelastic Demand } & \multicolumn{4}{|c}{ SH2 } \\
\cline { 2 - 5 } Elastic Demand & $\mathbf{4 - d e c}$ & $\mathbf{1 7 - d e c}$ & $\mathbf{1 0 - a p r}$ & $\mathbf{1 0 - j u l}$ \\
\cline { 2 - 5 } & $-0.33 \%$ & $-0.34 \%$ & $0.00 \%$ & $-0.10 \%$ \\
\hline
\end{tabular}

were always under $3.5 \%$ for the stochastic version. Thus, the stochastic version is not only better in quality but in confidence, so we use its figures as a reference to valuate the benefits of having smart-grids capabilities to control up to $30 \%$ of the residential demand of energy.

Those figures show that having such control allows costs to be reduced in all hydroelectric scenarios: $4.7 \%$ (HB1), 3\% (EHT1,2) y $2.1 \%(\mathrm{SH} 1,2)$. Savings are relatively higher in the hydro standard HB1 scenario, but in absolute terms are much higher in those of drought. If all those savings were transferred to elastic demands, reductions of price could be around $25 \%$.

\subsection{Insights of operational changes}

In this section, we show some relevant technical details of those numerical solutions previously discussed. As we mentioned before, for each instance tested, four versions of the problem were solved. Problem versions that explore elastic demand simultaneously explore the usage of batteries. After analyzing solutions when elastic demand is available, batteries are never used to reduce production costs.

Regarding on how elastic demand is managed to reduce generation costs, we analyze two wind-power scenarios for the typical hydro HB1. For simplicity, we show results from deterministic versions. The wind-power scenario of 10-apr-2016 (leftmost of Figure 9) is particularly windy, so, the entire demand of the country can be fulfilled by complementing wind-power with some hydric. Moreover, the residual demand (demand minus wind-power) can almost be completed by using Salto Grande, except around moments of peak demand, where it must be complemented with Baygorria (first) and Palmar (later), because of the outflux-to-influxes relation between them. Figure 10 shows with solid lines how much energy is produced at each hour from each source. Salto Grande production function is represented with blue, Baygorria with red and Palmar with green. By controlling demands, it is possible to satisfy power requirements by solely using Salto Grande, whose updated production curve is also sketched in Figure 10 with a dashed blue line. Tracking

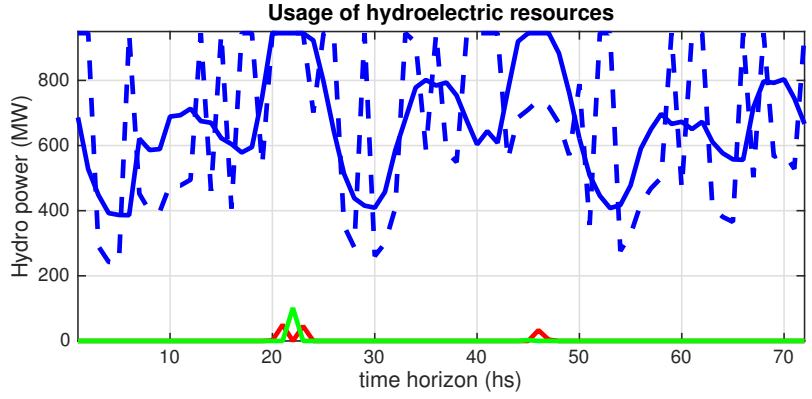

Figure 10 Hydroelectric power necessary to complement wind-power on 10-april-2016 [hydro-scenario HB1]

the dashed production line might look harder than the original scheme, however, being able of providing the necessary power through a single unit allows to modulate grid's frequency more easily than by coordinating three units. Recall that although there are rapid thermal units assimilable to ramping services (Table 2), fulfilling demand with renewable (not imported) power sources is a goal of the system, and coordinately managing distributed hydroelectric units is harder than modulating with ramping ones.

A similar situation happens on 4-dec-2016, although here, wind-power production is not as important as in the previous case, and several units are needed to fill the difference. However, the hydroelectric plant is still sufficient to provide the additional power.

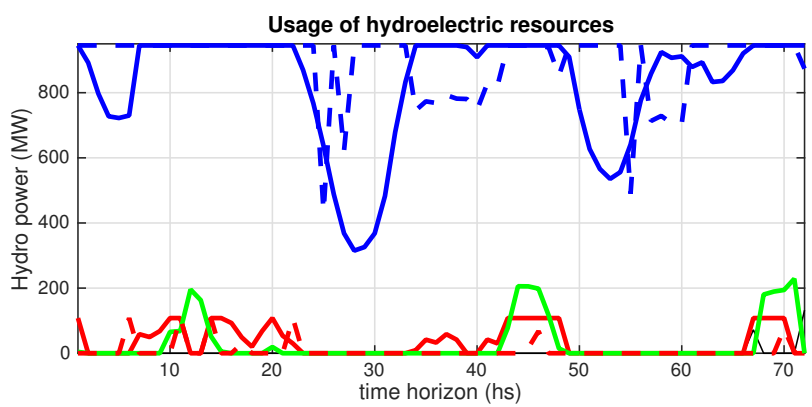

Figure 11 Hydroelectric power necessary to complement wind-power on 4-december-2016 [hydro-scenario HB1]

Observe in Figure 11 that during most of the daytime, Salto Grande is at its maximum production level (blue curvel, and it should be complemented with Baygorria (red), Palmar (green) and even with Bonete (black) by the end of the period. By moving demand, merely Salto Grande and Baygorria can complement the power. Observe that, once again, the scheme of units necessary to sustain the grid is reduced, in this case from four to two. Partial drought conditions of EHT1 blended with a normal (not abundant) wind-power scenario, like that of 17-dec-2016, impose complementing generation with fossil sources. In particular, the stochastic version at some instants makes 
use of: the CCP unit (as it main source), Palmar, Baygorria and Bonete (all hydros but Salto Grande), plus thermic units: Battle Motores, Punta del Tigre groups 1 and 2.

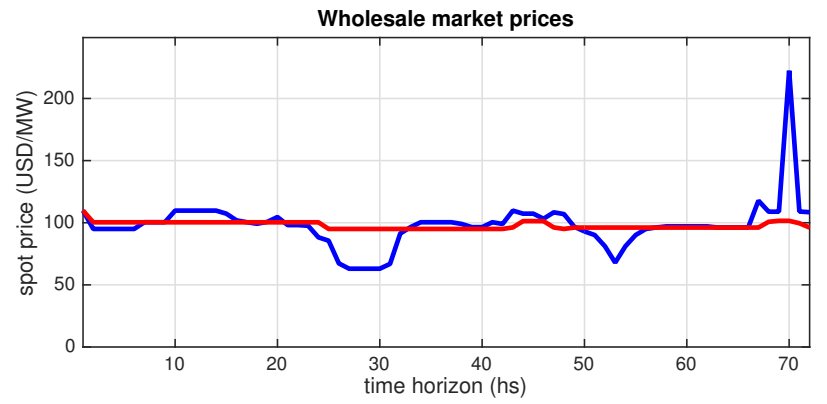

Figure 12 Evolution of wholesale market spot prices on 12-december-2016 [hydro-scenario EHT1]

Such diversity muddles spot prices setting, whose average over the set of trajectories spanned by the stochastic model is represented in Figure 12 with a blue line. It is worth mentioning that the spot peak at time 70 does not come from the variable cost of any unit but is the marginal of the whole system. A system that integrates time dependencies (e.g. ramp-up in the CCP, tandem electric dams along Río Negrol that may drift to overproduction to keep integrity.

After an optimal control of demand, the number of units necessary to manage de systems decreases, what flattens projected wholesale prices (red line), or, in economic terms, reduces wholesales market volatility.

\section{Conclusions and future work}

This document presents how classical optimization models were used to quantify the benefits of having smart-grids technologies, a fundamental component of smart-cities. Such benefits were computed upon a real-world scenario, the Uruguayan electricity market, a world leader in the usage of renewable energies, with over $96 \%$ of its electricity coming from these sources. Particularly, the country is facing the challenge of getting over $35 \%$ of its electricity from wind-power, a highly volatile source of energy.

Experimentation was developed assuming that $30 \%$ of the residential demand can be controlled, showing that if billed differentially, discounts could round $25 \%$. Large scale energy consumers can trade in the wholesale electricity market, which turns less volatile by controlling residential demands.

Residential users however, must contract with the public owned company (UTE), so a centralized mechanism as that described in this document is not only easy to be developed, but it is actually viable in Uruguay, where the state owned company is the sole residential distributor.

Regarding the particulars of the dispatch schedules, their results show that smart-grids not only allow reducing production costs, but also softness the stress to operate the grid. A secondary but highly desirable consequence of controlling demands to reduce costs, is that the set of components necessary to provide power to the grid is lower than in regular conditions. In addition, there are fewer cycles of activation/deactivation of components.

Demand is usually headed apart from peaks, so the resulting dispatch removes stress from passible components of the power grid (conductors, voltage transformers, etc). Experiments developed so far are punctual, and simulate specific days taking its parameters from historical data sets. A promising line of work consists in expanding the software components developed so far, to run instances along larger periods of time. Hence, historical information could be used to evaluate results over months or years. The analysis of the solutions shows that most of the savings are consequence of a better use of hydraulic resources. Therefore, it is probable that the sustained application of such controls makes the system more immune against falling in drought conditions, in which costs are much higher. Another line of future work is the integration of solar-power among the sources of uncertainty.

\section{Acknowledgments}

This work was partially supported by ANII (Uruguay), by PEDECIBA-Informática (Uruguay), and by the STIC-AMSUD project 15STIC-07 DAT ljoint project Chile- France-Uruguay). Special thanks to Alfredo Piria and Julián Viera for their commitment and contributions during the realization of this work.

\section{References}

[1] C. Risso, "Using smart-grids capabilities as a natural hedge against novel risks coming from non-conventional renewable electricity generation," in Ibero-American Congress on Information Management and Big Data, Soria, Spain, 2018.

[2] REN21, "Renewables 2018 global status report," REN21 Community, Paris, France, Tech. Rep., 2018.

[3] R. Karki and R. Billinton, "Cost-effective wind energy utilization for reliable power supply," IEEE Transactions on Energy Conversion, vol. 19, no. 2, pp. 435-440, Jun. 2004.

[4] J. M. Morales, A. J. Conejo, H. Madsen, P. Pinson, and M. Zugno, Integrating Renewables in Electricity Markets, 1st ed. New York, USA: Springer US, 2014.

[5] M. Joosa and I. Staffell, "Short-term integration costs of variable renewable energy: Wind curtailment and balancing in britain and germany," Renewable and Sustainable Energy Reviews, vol. 86, pp. 45-65, Apr. 2018. 
[6] N. Li, L. Chen, and S. H. Low, "Optimal demand response based on utility maximization in power networks," in 2011 IEEE Power and Energy Society General Meeting, Jul. 2011, pp. 1-8.

[7] A. Mohsenian-Rad and A. Leon-Garcia, "Optimal residential load control with price prediction in real-time electricity pricing environments," IEEE Transactions on Smart Grid, vol. 1, no. 2, pp. 120-133, Sep. 2010.

[8] F. Paganini, P. Belzarena, and P. Monzón, "Decision making in forward power markets with supply and demand uncertainty," in $201448^{\text {th }}$ Annual Conference on Information Sciences and Systems (CISS), Mar. 2014, pp. 1-6.

[9] W. Jeon, A. J. Lamadrid, J. Y. Mo, and T. D. Mount, "Using deferrable demand in a smart grid to reduce the cost of electricity for customers," Journal of Regulatory Economics, vol. 47, no. 3, pp. 239-272, Jun. 2015.

[10] J. Y. Mo and W. Jeon, "How does energy storage increase the efficiency of an electricity market with integrated wind and solar power generation?-A case study of Korea," Sustainability, vol. 8, no. 10, 2017

[11] L. Jiang and S. Low, "Multi-period optimal energy procurement and demand response in smart grid with uncertain supply," in 2011 $50^{\text {th }}$ IEEE Conference on Decision and Control and European Control Conference, Dec. 2011, pp. 4348-4353.

[12] I. Atzeni, L. G. Ordóñez, G. Scutari, D. P. Palomar, and J. R. Fonollosa, "Demand-side management via distributed energy generation and storage optimization," IEEE Transactions on Smart Grid, vol. 4, no. 2, pp. 866-876, Jun. 2013.

[13] Y. Wu, V. K. N. Lau, D. H. K. Tsang, L. P. Qian, and L. Meng, “Optimal energy scheduling for residential smart grid with centralized renewable energy source," IEEE Systems Journal, vol. 8, no. 2, pp. 562-576, Jun. 2014.

[14] S. Montes de Oca, P. Belzarena, and P. Monzón, “Optimal demand response based on time-correlated utility in forward power markets," in 2015 IEEE PES Innovative Smart Grid Technologies Latin America (ISGT LATAM), Oct. 2015, pp. 597-602.

[15] C. Risso and G. Guerberoff. (2018, May. 10) Nonparametric optimization of short-term confidence bands for wind power generation. [Online]. Available: https://arxiv.org/abs/1805.04474v1

[16] S. de Mello, G. Cazes, and A. Gutierrez, "Operational wind energy forecast with power assimilation," $14^{\text {th }}$ International Conference on Wind Engineering, Porto Alegre, Brazil, 2015. 